\title{
ALIVE AND KICKING-BUT WILL QUALITY MANAGEMENT BE AROUND TOMORROW? A SWEDISH ACADEMIA PERSPECTIVE
}

\author{
BJARNE BERGQUIST, RICKARD GARVARE, HENRIK ERIKSSON, \\ JACOB HALLENCREUTZ, JOSTEIN LANGSTRAND, \\ ERIK VANHATALO, THOMAS ZOBEL
}

\section{INTRODUCTION}

In the 1980s and 1990s the Japan originated quality movement with its emphasis on customer focus was largely seen as the leading way for effective change towards competitiveness. Focus has since shifted from Total Quality Management and models of Business Excellence to Six Sigma improvement and Lean Management in parallel with behaviorally oriented change programs with emphasis on leadership. We argue that it still remains unclear in the literature whether quality management (QM) is a collection of techniques, a management philosophy, a management method, a strategy, a theory for managing only quality and service processes, a master theory for managing the entire enterprise - or all of the above? From this point of view, several scholars have concluded that management concepts cannot be narrowly defined but should rather be considered multi-dimensional constructs (Pettersen, 2009; Hellsten and Klefsjö, 2000; Dean and Bowen, 1994).

The time when the quality domain was confined to the inspection personnel of the manufacturing industry is long gone. Throughout the 20th century managing for quality has moved from being an arena for specialists understood and appreciated by few to being repackaged to a top management concept in the form of Total Quality Management (TQM). In the TQM guise, quality was often considered to be panacea for organizational problems, and as such, it did not take long before being designated a fad status (van der Wiele et al, 2001; Young \& Wilkinson, 2001), whereas others criticize different aspects of TQM, for instance lack of common definitions and its cure-all prominence (Bergquist et al. 2005).

In the public domain of many western countries, especially in health-care, quality management seems to hold a status similar to the popularity peek seen in manufacturing in the late 1980s. The ability to meet product specifications or to satisfy customer needs have other meanings in service production, where the products are co-produced by the customers. Product quality may also have a different interpretation in situations where branding is increasingly more important for sales and for customer satisfaction. The on-going globalization and 
the rising competitive pressures continuously change how organisations are run. Growing environmental concerns by governments, consumers and other stakeholders add to the pressure to change. Constant change is an oxymoron describing the current organizational environment and perhaps also the QM discipline.

Within a world of change, the role of quality must relentlessly be redefined so that its current nimbus remains. New management concepts are frequently introduced, and while some are merely new makeups on yesterday's concepts, some remakes are more extensive. Pyzdek (1999) stated, after summarizing some criticism against the field of $\mathrm{QM}$, that professionals within this discipline constantly need to improve the knowledge of quality and the methodologies for attaining it to manage the changing concept of QM. Foley (2004) claimed that, due to the critics of QM, many consultants and quality promotion institutions are trying to expunge "quality" from their lexicon, and that QM now regularly appears under a different guise, often with a new set of gurus and new "catchy" slogans; but in substance it remains the same. The quality movement has a long and complex history, and its evolution from the industrial revolution to present day has been interpreted in many different ways and stages, from Quality Control to Total Quality Management and beyond. Boaden (1997) stated that "attempting to define TQM is like shooting at a moving target. As it is more widely practised, and other initiatives emerge, the emphasis on different aspects change." Against this backdrop, we saw it fit to study how QM management scholars in Sweden view the discipline, and let them speculate what role, if any, quality management will play in the future. The purpose of this article is to investigate how QM is perceived today by scholars at three Swedish universities, but also how and into what $\mathrm{QM}$ is expected to develop into in twenty years.

We present a theoretical background to QM, followed by a brief discussion about the chosen method. Then we present the results from the conducted workshops and an analysis. Finally, we provide some general conclusions and a discussion.

\section{THEORETICAL BACKGROUND}

There are many terms that indicate the same thing: Management concepts, management recipes, or management models. Regardless of the chosen term, the reader will probably know that QM is not the only one of these out there. Following Dean and Bowen (1994), we define a management concept as a multidimensional management approach consisting of principles, practices and techniques. At the most abstract level, a 'principle' in this context is an organizational norm that underpins the various activities related to the concept at hand and guides people's attention towards certain aspects of the organization. At the other end of the scale, the least abstract and most readily observable of these three are the techniques. These are usually quite specific and well defined. The various techniques associated with a management concept are more or less 
related to one another. Depending on this relatedness, the techniques are aggregated to form 'practices'.

According to Furusten (1999), management concepts are developed in three steps. First, a management practice is observed in one or several organizations. The observations are then analysed to establish patterns and relationships between variables. Finally, the outcome of the analysis is transferred to a text of some sort; usually a book. In order to find relevance in contexts outside the one that has been observed, the text is decontextualized; what is context specific in terms of material representation and how the practice is described in the context of origin is detached from the conceptualized practice (Røvik, 2007; Lillrank, 1995). The finished 'product' (management concept) is less dependent on context and therefore more easily transferable and applicable for other contexts. However, since it has been stripped of contextual dependencies, there are several questions that are left open for interpretation, which will have implications for its application.

Sahlin and Wedlin (2008) discuss three modes of dissemination. Most closely linked to the supplier side of idea dissemination is the broadcasting mode. This mode has many similarities to Rogers' theory of diffusion (Rogers, 1995), indicating that there is one, mainly unchanging, idea that spreads from a single source. Another mode of dissemination is mediation, which also is closely linked to the conception of 'idea suppliers', the meaning being that there are persons and organizations that promote certain ideas and help their dissemination. The third mode of dissemination is the chain mode, indicating that the idea spread from organization to organization, in a sequential manner. With this perspective, there is no particular supplier of ideas; rather each organization has an active role in disseminating the idea. These three modes of dissemination will have different effects on the idea that is communicated.

Just as all fashions and trends, the popularity of management concepts goes up and down. We can see 'new' concepts come and go, and these will eventually be replaced by 'newer' ones (Abrahamson, 1996; Barley and Kunda, 1992; Giroux and Landry, 1998). As with every other fashion, management concepts are usually contrasted to an 'old' paradigm and thereby implied as a 'modern' solution, which in turn contributes to further their dissemination (Røvik, 2000).

While the abstract descriptions in the popular management literature may be easily disseminated and attractive, they are not directly applicable without some adaptation; the contextualization of management concepts becomes a mirror image of the de-contextualization process, in which the abstract description is translated into a specific practice. Given this chain of translations, it is unlikely that the initial practice and the final one will be identical, leading to large variation in how specific management concepts are interpreted.

From a practitioner point of view, one might disregard the diversity of descriptions in academic literature as being merely an 'academic' discussion that has no impact on practice. This may be true, to some extent, but the argument 
alone does not confine the tendency of diversity to academia. In fact, the same variability is present in industry. Based on a survey among Swedish production managers, Poksinska et al. (2010) demonstrate that the application of management concepts differ significantly between organizations as well.

Organisations have for many years focused on the quality of their products in order to be competitive. Different initiatives to improve the quality of products and services have evolved. The early focus, at the beginning of the twentieth century, was on inspection, which included checking that the manufactured products met the specifications. During the past few decades the focus in organisations has shifted from inspection to quality control. Through quality control organisations are trying to identify, directly in the process, flaws that can be corrected before producing too many products that do not meet the specifications. In the evolution of quality, the focus on quality has moved even further upstream in the process. Quality assurance has become a recognised term for planning and preventing problems at the source before starting to manufacture products. The latest focus in the evolution of quality is considered to be on Quality Management (QM), which involves the application of quality management principles to all aspects of the organisation, including customers and suppliers, and their integration with the key business processes (Dale, 1999).

However, there are also other views of the evolution of quality than the singlepath evolution presented by Dale (1999). Kroslid (1999) identifies a dual-path framework with two different schools of QM, "the deterministic school of thought" and "the continuous improvement school of thought". The deterministic school of thought has developed from a deterministic view of reality, with a belief in the existence of one best way, while the continuous improvement school of thought is founded on a reality full of variation, with an awareness of the improvement potential in every aspect of work. Kroslid (1999) argues that China, Japan, South Korea, Sweden and the United States, in terms of their current national approach, predominantly position themselves within the continuous improvement school of thought, while Australia, Brazil, Germany, Great Britain, Italy, Norway and Saudi Arabia belong more to the deterministic school of thought. In particular, Japan, Sweden and the United States are in terms of development on a "high" level within the continuous improvement school of thought, with a great focus on practices based on culture.

Sila \& Ebrahimpour (2002) review, that the most frequently covered QM factors in the literature are (after analysing 347 survey articles published between 1989 and 2000):

- Customer focus and satisfaction

- Quality information and performance measurement

- Process management

- Continuous improvement and innovation 
- Employee training

- Teamwork

- Employee involvement

- Leadership and top management commitment

Different definitions of QM have been presented over the years. Oakland (1993) states that QM is "an approach for improving the competitiveness, effectiveness and flexibility of a whole organisation". Dale (1999) describes QM, in accordance with ISO 8402, as "a management approach of an organisation, centred on quality, based on the participation of all its members and aiming at long-term success through customer satisfaction, and benefits to all members of the organisation and to society". Dahlgaard et al. (1998), on the other hand, define QM as "a corporate culture characterized by increased customer satisfaction through continuous improvement, in which all employees in the firm actively participate". Shiba et al. (1993) argue that QM is "an evolving system of practices, tools, and training methods for managing companies to provide customer satisfaction in a rapidly changing world". Foley (2004) condenses some of the criticism against quality management and claims:

- is not universally or even widely accepted

- has no generally accepted definition or agreed content

- does not have a theoretical foundation

- has not found a place in mainstream Western management literature

- has failed to deliver promised results

\section{METHODOLOGY}

The data collection of opinions from scholars working with quality management at the three universities was conducted using three independent workshops at three Swedish universities. The sole purpose of the workshops was to perform structured brainstorming sessions. Affinity diagrams were used to provide a structure for the activity and to document the results. The method used was tailored for this event based on generic methods for structured brainstorming and affinity analysis, see for instance Brassard et al (2002). In the Luleå workshop, the invitation to participate was sent to nine people within the Quality Technology \& Management research group. Of these, five persons attended the actual workshop (two professors, two senior lecturers and one PhD student. The Linköping workshop was performed in a similar fashion as that in Luleå. All members of the division for Quality Technology and Management were invited to participate, and six persons attended. Among these were three PhD students, 
two senior lecturers and one professor. At Chalmers, all members of the division Quality Sciences were invited, and seven persons (three $\mathrm{PhD}$ students, two researchers, one assistant professor and one associate professor) attended. Below we describe the general steps of the method used. The brainstorming sessions were organized around the two questions:

1) What does Quality Management stand for today?

2) What will Quality Management stand for in 20 years?

\section{The structure of the workshop and the brainstorming session}

- Preparation: A few days prior to the workshop, the purpose and the two research questions to be discussed was sent to the participants. In the Luleå workshop, the invitation to participate was sent to nine people within the Quality Technology \& Management research group. Of these, five persons attended the actual workshop (two professors, two senior lecturers and one $\mathrm{PhD}$ student.

- Start: At the start of the workshop, the research questions were written on a whiteboard and the workshop methodology was presented to the participants. Everyone around the table then freely and shortly expressed what thoughts they had, related to the workshop, and this was done without anyone taking notes.

- Silent individual work: The next phase included silent work, where all wrote answers to the two research questions on white Post-It ${ }^{\circledR}$ notes. There were no special rules for the answers or the number of notes at this point. Answers from this phase could be expressed as, e.g., values, principles, models, tools, expressions of opinion and so on. After some time the participants patched the notes on the whiteboard below the current research question. This was done without guidance.

- Grouping of notes: First all participants silently assisted in grouping the notes. The silence was broken when there was a need to discuss the grouping of a note with several possible belongings. In such cases, the most appropriate grouping was decided after a short discussion.

- Headings for groups: When all notes had been grouped or considered as single outliers, the groups were given headings written on yellow notes. Some related yellow headings were grouped together in an additional iteration, and were given headings on pink notes.

- Discussion and revision: The group reviewed the outcome for each research question and some headings were revised and some notes were moved to fit under another heading. Some general conclusions were drawn based on the outcome and a short discussion. 
- Documentation: The outcome was documented electronically immediately after the workshop.

Moreover, the websites of each research group were studied in order to understand how they are presenting themselves and the subject of Quality Management.

\section{RESULTS}

The results from the three workshops are presented in the three tables below together with some brief comments for each brainstorming session.

\subsection{Chalmers University of Technology - "the searchers"}

The notes clusters from the workshop at Chalmers are given in Table 1. The department of quality sciences at Chalmers was started in 1999 with support from the Swedish bearing manufacturer SKF. The group focuses on developing knowledge and competence in quality management and technology and its supporting methods for use in the ongoing improvement process in the Swedish society. The department's website statement is that "quality management and technology means to continuously strive to fulfil or exceed the needs and expectations of external and internal customers in all processes in which everyone are committed to their continuous improvement."

The participants at Chalmers reports a core set of features constituting QM today: System Thinking, Customer focus, Continuous Improvement, Variation Management, Change Management and Process Management. As such, Chalmers aligns to a QM mainstream, see for instance Sila and Ebrahimpour (2002), Oakland (1993), Dale (1999) and Dahlgaard et al. (1998). However, in 20 years, the group portrays a wide set of parts that are there today, but in this scenario will grow in importance. Such features include innovation, sustainable development, sectorial QM, quality in life and these features will substitute concepts like ISO, Lean and Six Sigma.

In the future, quality science is seen to be integrated and embedded. But the direction is not clear. The participants of the Chalmers workshop can be seen as "the searchers", where QM continues more or less as it is seen today, but with an increased focus on integration, into a systemic perspective. As such QM moves into a concept where the focus is on a greater whole while keeping the quality toolbox intact. The participants proclaim that in the future "Quality management should include quality of life". In 20 years quality is about "survival" and "change", but it is also about "standardization" and "toolbox". The theorists discuss the role of quality within a world of change and the department of quality sciences at Chalmers is no exception. A conclusion of the workshop is that the views of the direction forward for QM differ. 
Table 1-Notes clusters from the workshop at Chalmers University of Technology

\begin{tabular}{|ll|}
\hline QM today & QM in 20 years \\
\hline System Thinking & System Thinking \\
Customer Focus & Customer Satisfaction/Customer Participation \\
Continuous Improvement & Continuous Improvement/Learning \\
Variation & Variation Management \\
Change Management & Change Management \\
Processes & Process Management \\
Leadership & Quality in Product Development \\
Statistics/Facts & New Methodologies \\
Quality Assurance & Quality in Innovation \\
ISO & Sustainable Development \\
Standardization & Sectorial Quality Management \\
Lean & Quality in Life \\
Six Sigma & Quality Assurance \\
Methods & None \\
Responsibility & \\
Other Fields & \\
\hline
\end{tabular}

Table 2 -Notes clusters from the workshop at Lulea University of Technology

\begin{tabular}{|l|l|}
\hline QM today & QM in 20 years \\
\hline Umbrella discipline & Diffusion \\
Customer Focus & Diversification \\
Improvement focus & Prolongation \\
Effectiveness and efficiency & "Greening" \\
Values, Methods, Tools & Integration \\
Undefined concept & Theory-based \\
Introspective & Miscellaneous \\
Normative & \\
Miscellaneous & \\
\hline
\end{tabular}

\subsection{Luleå University of Technology - "the doubters"}

The notes clusters from the workshop in Luleå are given in Table 2. The website describes the group's activity as to “...develop and spread methodologies and methods for continuous improvement of processes and products to create a sustainable society.” The participants at the Luleå workshop report a core set of features constituting QM today similar to that of Chalmers although slightly different terms are used: Umbrella discipline (i.e. System Thinking), Customer focus, Improvement focus, Effectiveness and efficiency. The QM discipline is also viewed as somewhat introspective and normative. However, the department also airs pessimistic and doubtful future scenarios, where it is forecast that QM might be diffused or even non-existent. If not, a focus on sustainable development and CSR will have turned the subject more "green", but fundamental questions such as "Do we still speak of Quality Management?" are raised. At Luleå we find "the doubters", hesitating about the future of the QM discipline. The participants in 
Luleå join critics like Foley (2004) and highlight problems such as that QM has no coherent theory, no generally accepted definition or theoretical foundation, and has failed to deliver promised results.

\subsection{Linköping University - "the technocrats"}

The notes clusters from the workshop at Linköping University are given in Table 3.

Table 3 - Notes clusters from the workshop at Linköping University

\begin{tabular}{|l|l|}
\hline QM today & QM in 20 years \\
\hline Traditional Quality & Seeing the whole, processes \\
The paper reality (management systems/ISO & Service quality \\
$9001)$ & The customer as co-creator, long term \\
Passive customer focus & relations \\
Active customer focus & Integration/systems perspective \\
Organising/organisation & IT \\
LEAN business (production) development & Sustainable development \\
Employees & Flexibility/Innovation/Renewal \\
Values & Employer focus \\
Problems & Quality development \\
Miscellaneous & Miscellaneous \\
\hline
\end{tabular}

The participants at Linköping University also report a similar core set of features constituting QM of today. The participants discuss a perceived "gap between business and academia" and one note calls the subject "amoeba". More structural approaches are advocated - a conclusion is that the Linköping group sees QM in more technocratic terms, but we also recognize the systems integration aspect, as also indicated at the Chalmers workshop. Linköping forecasts that in twenty years the subject QM still consists of a core based on traditional quality technology - it is "a structure integrated in practice" and might even consist of "more standards".

\section{ANALYSIS}

Boaden (1997) states that "attempting to define QM is like shooting at a moving target" and this study strengthens that metaphor. Hence, the results of this study should also be viewed as a "snapshot" of QM today and a prognosis of the future state. By using "Wordle" - a shareware for generating "word clouds" from text we can visualize the most frequently used words used by the three universities to describe QM today (Figure 1) and in twenty years (Figure 2). The words "quality", "management" and "customer" stand out in both word clouds. However, it can be observed that the word "improvement" is in fourth place to describe QM today in Figure 1, but it is substituted by "development" in the cloud describing QM in twenty years in Figure 2. 


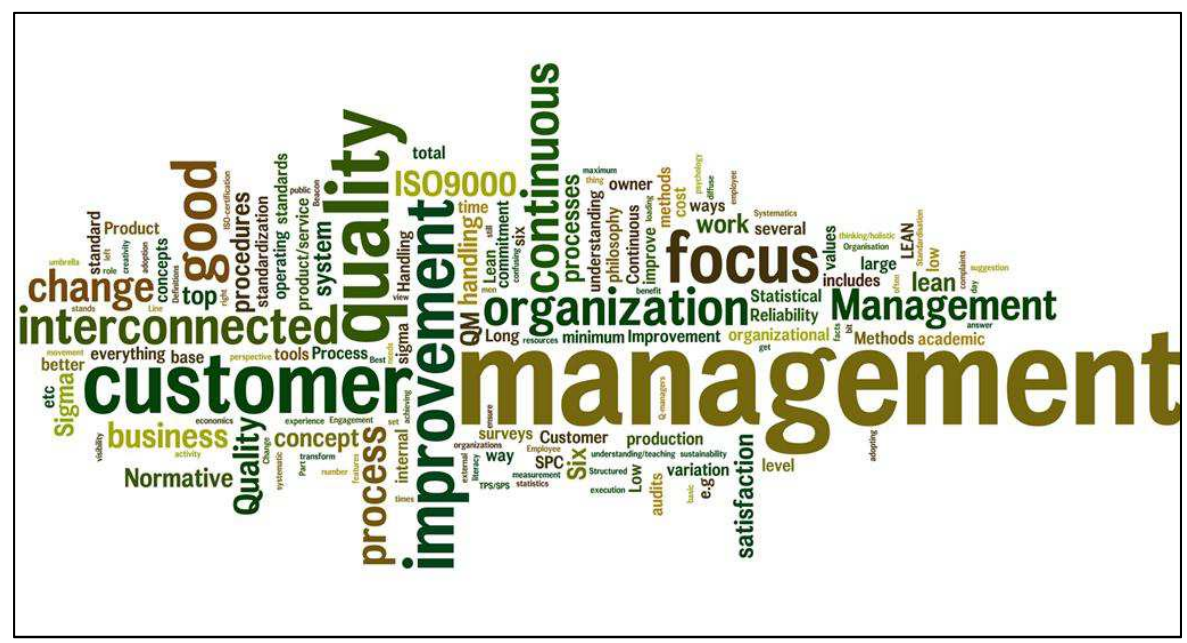

Figure 1 - Word cloud for QM today for all three universities

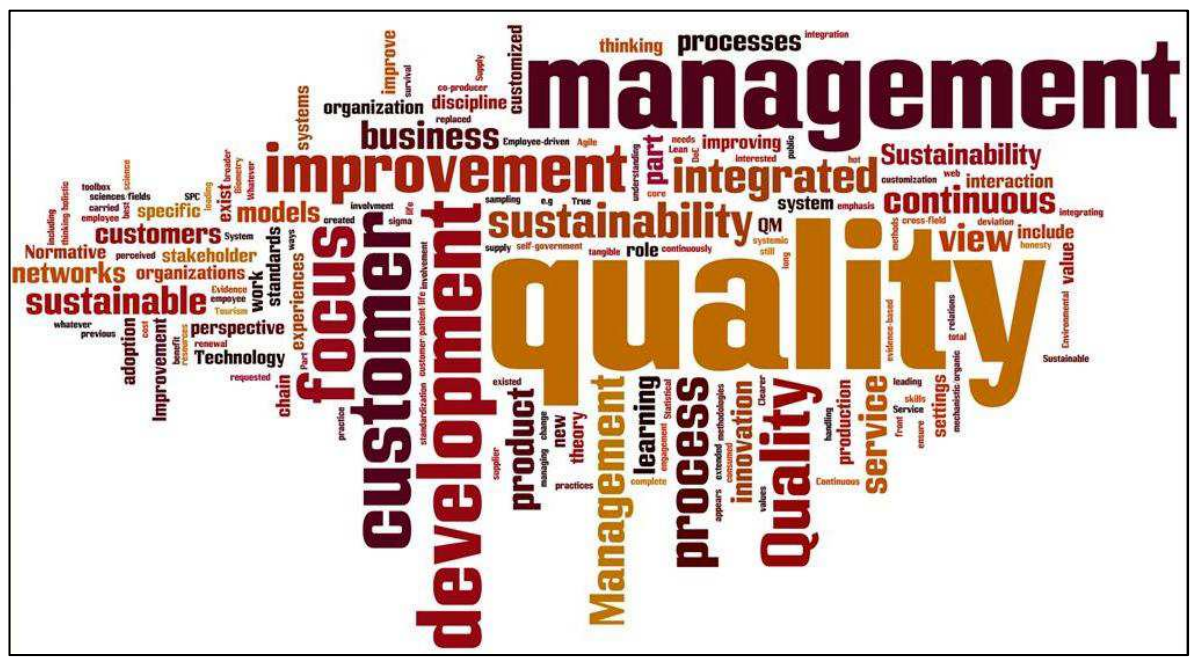

Figure 2 - Word cloud for QM in 20 years for all three universities

Moreover, as the questions in the workshops concerned quality management, we also did a "Wordle" excluding the word of "quality" and "management". The results of these two "Wordle" are shown in Figure 3 and 4.

A conclusion from Tables 1-3 and Figures 1-4 is that although the three universities mention tools in QM such as statistical process control, the focus on both the notes clusters and in the word clouds is on what Dean and Bowen (1994) define as QM principles. We also see that the participants mention "other" management concepts and disciplines such as Lean and Sustainable development while discussing QM. The three universities forecast that a merger of these concepts and disciplines in the future. 


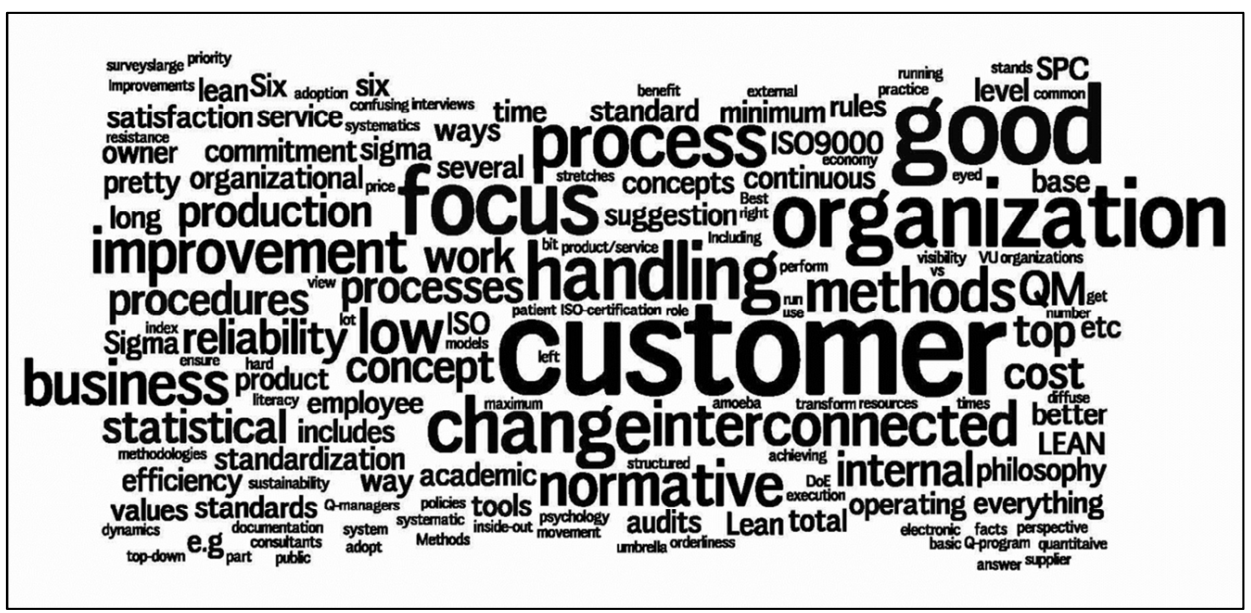

Figure 3 - Word cloud for QM today for all three universities, excluding "quality" and "management"

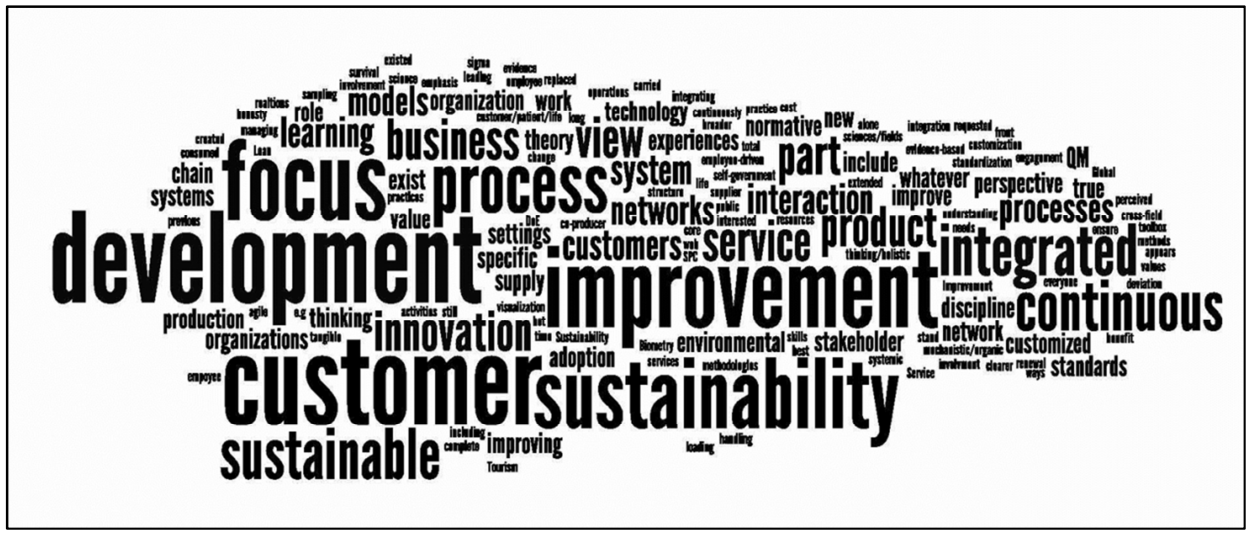

Figure 4 - Word cloud for QM in 20 years for all three universities, excluding "quality" and "management"

\subsection{Quality Management today}

The results indicate that the differences, between the three universities taking part in this study, are small. Obvious words like "quality", "management", "customer", "processes" and "improvement" along with widespread concepts such as Lean, Six Sigma and ISO 9000 are identified by all three. Thus, although there is no coherent taxonomy there seems to be a mutual understanding of what QM currently contains. All three universities seem to follow the continuous improvement school of thought (Kroslid, 1999). However, it can be observed that Chalmers highlight "change management" as a separate area of interest and Luleå applies a more critical approach to the subject QM as such, whereas improvement and the concepts Lean and Six Sigma where more frequently seen 
at the Linköping workshop. The differences are nonetheless small and may be related to views of individuals in these groups and the general result is the relative agreement of what QM constitutes, rather than the differences.

\subsection{Quality Management in 20 years}

There is a core of mutual understanding of what QM is composed of in twenty years, but the suggested direction of QM development diverges between the workshops. The commonality is seen in a direction or integration of sustainable development that is increasingly more important. Integration is also a common theme, although both the Luleå and Chalmers workshops saw an alternative scenario, where diversifications of different sub-subjects within QM continue.

The differences seen from the workshops can be seen as alternative development patterns. At Chalmers, we find "the searchers" envisioning a change into a more systemic concept, integrating parts that today are seen and developed individually under the QM umbrella into a QM system. In Linköping "the technocrats" hold on to the core of quality technology. Up north in Luleå we find "the doubters" forecasting a possible scenario that the subject as such might be dead and forgotten in twenty years.

Despite the limitations of this study, it can be concluded that there are many similarities among the universities taking part in this study and no profound differences on what quality management is today. But the thoughts about the future diverge in three: the searchers, the technocrats and the doubters. But there is probably no revolution around the corner - "the core remains the same" as one post-it note from Linköping puts it. Luleå is the only participant questioning the subject as such. A move from the tool boxes towards a more holistic management approach focusing on sustainability, integration and change could perhaps be seen as the overall forecast from all universities.

\section{CONCLUSION}

We conclude that the way QM is perceived today at the three participating universities is similar. QM is today described as wide discipline consisting of a set of core of principles that in turn guide the content of the QM method toolbox. Examples of core principles on which all three universities clearly agree are: Customer focus and Continuous Improvement. The three universities also agree that the QM discipline is constantly, but slowly, changing and today QM is "driving while under the influence of" other management concepts and disciplines, such as: Lean production and Six Sigma. The wider stakeholder view within QM also leads to a shift towards research closely related to other disciplines, e.g. sustainable development and corporate social responsibility.

The view on the future of QM differs more among the three universities. Although all forecast a possible scenario of further integration with other disciplines like sustainable development, the forecasts of the development 
direction is more diffuse. We conclude that the three universities convey three possible development directions for QM in the future:

- The "searchers" at Chalmers University of Technology propose that QM can find its place within a discipline $X$ where QM will contribute to a "greater whole" while keeping the quality toolbox intact.

- The "technocrats" at Linköping University suggest that QM returns to its roots and consist of a core based on traditional quality technology toolbox with its methods and tools.

- The "doubters" at Luleå University of Technology forecast a risk that QM, as it is today, may seize to exist and instead the research may be conducted within other disciplines or under a different concept name than QM.

\section{DISCUSSION}

A shift for QM towards a focus on sustainable development is evident at all three universities. This move is somewhat surprising since none of the departments' website mention anything in this regard today. In Luleå, this development started in year 2000 when Professor Rick Edgeman visited the department and held a PhD course with focus on sustainable development. A discussion started that led to a merger between the quality technology unit and the environmental management unit. Even though the concepts of "sustainable development" and "sustainability" were often mentioned at the workshops, it should be noted that we cannot be certain that the participants mean the same thing since these concepts by themselves are broad and have many definitions. There is often some confusion when these concepts are discussed in various forums. For example, sustainability has been a central concept at the quality management and organizational development (QMOD) conference the last two years. The sessions relating to sustainability has often consisted of a mix of presentations that either includes environmental sustainability, economic sustainability and socio-political sustainability in the concept or presentations that use the term sustainable for describing long term survival of an organization.

A possible shift towards the sustainable development area will probably not be without problems for the quality management departments. Since the quality area is mostly concentrated on issues and phenomena connected to organizations rather than overarching societal issues, we can assume that a shift will be towards organizations' contributing to suitable development. Today, this area is commonly referred to as corporate social responsibility (CSR) (ISO, 2010). The CSR field of research seems to already today interest scholars coming from various backgrounds, at least if it is assumed that authors mainly publish their work in journals within their main discipline (Ranängen and Zobel, 2012). The most dominating discipline is corporate environmental management represented foremost by core journals within this field such as for example Journal of 
Business ethics, Corporate Social Responsibility and Environmental Management, Corporate Governance and Journal of Cleaner Production. If scholars in quality technology want to successfully find their place in the CSR field, they have to carefully analyze how they best can contribute to the already existing research.

The future will tell if quality management scholars will turn their attention towards sustainability issues and what the impediments and contributions will be. One example of a problematic area that at the same might be worthy of scholarly interest is the role of process orientation and process management in organizations' work with sustainable development. Previous studies have shown that major elements of this work, at least the environmental related elements, is conducted in the context of environmental management system (EMS) (Zobel, 2010), often in accordance with the international standard ISO 14001, which follows a similar path of development as the ISO 9000-series. In practice, it has been found that continuous environmental improvements in the EMS context often are based on identified environmental aspects. These aspects are mostly connected to organizational functions or aggregated for the whole organization. Objectives, targets and action plans are then established based upon the aspects, and hence they are established with an environmental aspect focus rather than a process focus, which has been identified as central to quality management by the departments in Linköping and at Chalmers.

Another challenging area for quality management in the future might be to address issues in innovation management (identified by Linköping and Chalmers as important in 20 years) in an organizational context where continuous improvements is a central concept. Previous conceptual research has shown that organizational management based on continuous improvements can potentially have positive effects initially but that such a management system limits the organizational focus to the development of current production systems in very small steps rather than to explore larger innovations that are more discontinuous in nature (Könnälä and Unruh, 2007). We can possibly see signs of this development in empirical research, in which it has been found that management systems based on continuous improvements lack real influence on the product development process (Kautto, 2006; Schylander and Martinuzzi, 2007). 


\section{REFERENCES}

Abrahamson, E. (1996), "Management Fashion", The Academy of Management Review, Vol. 21 No. 1, pp. 254-285.

Barley, S. R. and Kunda, G. (1992), "Design and devotion: Surges of rational and normative ideologies of control in managerial discourse", Administrative Science Quarterly, pp. 363-399.

Brassard, M., Finn, L., Ginn, D., Ritter, D. (2002), The Six Sigma Memory Jogger, $G O A L / Q P C$.

Bergquist, B., Fredriksson, M. and Svensson, M. (2005), “TQM Terrific Quality Marvel or Tragic Quality Malpractice”, The TQM Magazine, Vol. 17, No. 4, pp. 309-321.

Boaden, R. J. (1997), “What is Total Quality Management... And does it matter?", Total Quality Management, Vol. 8, No. 4, pp. 153-171.

Dahlgaard, J. J., Kristensen, K. and Kanji, G. K. (1998), Fundamentals of Total Quality Management, London, Chapman \& Hall.

Dale, B. G. (1999), Managing quality, Oxford, Blackwell Publishers.

Dean, J. W. and Bowen, D. E. (1994), "Management theory and total quality. Improving research and practice through theory development", Academy of Management Review, Vol. 19 No. 3, pp. 392-418.

Foley, K. (2004), Five essays on quality management, Presented in honor of Homer Sarasohn, Standards Australia International Ltd., Sidney.

Furusten, S. (1999), Popular management books - How they are made and what they mean for organisations, London, Routledge.

Giroux, H. and Landry, S. (1998), "Schools of thought in and against total quality", Journal of Managerial Issues, Vol. 10 No. 2, pp. 183-203.

Hamschmidt J, and Dyllick T. (2001), "ISO 14001 - Profitable? Yes! But is it ecoeffective?”, Greener Management International, Vol. 34, pp. 43-53.

Hellsten, U. and Klefsjö, B. (2000), "TQM as a management system consisting of values, techniques and tools", TQM Magazine, Vol. 12, No. 4, pp. 238-244.

ISO (2010), Guidance on Social Responsibility (ISO 26000:2010, IDT).

Kautto P. (2006), "New instruments - old practices? The implications of environmental management systems and extended producer responsibility for design for the environment", Business Strategy and the Environment, Vol. 15, No. 6, pp. 377-388.

Kroslid, D. (1999), In search of quality management. Rethinking and reinterpreting, Doctoral thesis. Division of Quality Technology and Management, Linköping University. 
Könnölä, T. and Unruh, G. C. (2007), "Really changing the course: the limitations of environmental management systems for innovation", Business Strategy and the Environment, Vol. 16, No. 8, pp. 525-537.

Lillrank, P. (1995), "The transfer of management innovations from Japan", Organization studies, Vol. 16 No. 6, pp. 971-989.

Oakland, J. S. (1993), Total Quality Management. The route to improving performance, 2nd ed. Oxford, Butterworth-Heinemann.

Pettersen, J. (2009), "Defining lean production: some conceptual and practical issues", The TQM Journal, Vol. 21 No. 2, pp. 127 - 142.

Poksinska, B., Pettersen, J., Elg, M., Eklund, J. and Witell, L. (2010), "Quality improvement activities in Swedish industry: drivers, approaches, and outcomes", International Journal of Quality and Service Sciences, Vol. 2 No. 2, pp. 206-216.

Pyzdek, T. (1999). “A road map for quality beyond control”, Quality Progress, Vol. 32, No. 12 , pp. 33-38.

Ranängen, H., and Zobel, T. (2012). "Corporate social responsibility in industries utilizing natural resources: a review with focus on implementation", Working paper. Luleå University of Technology, Environmental Management.

Rogers, E.M. (1995), Diffusion of innovations, New York, Free press.

Røvik, K.A. (2000), Moderna organisationer: trender inom organisationstänkandet vid millennieskiftet. Malmö, Liber. (In Swedish)

Røvik, K.A. (2007), Trender og translasjoner: Ideer som former det 21. århundrets organisasjon. Oslo, Universitetsforlaget. (In Norwegian)

Sahlin, K. and Wedlin, K. (2008), "Circulating Ideas: Imitation, Translation and Editing”, In Greenwood, R., Oliver, C., Sahlin-Andersson, K. and Suddaby, R., (eds.), The SAGE Handbook of Organizational Institutionalism. London; California; New Delhi; Singapore: SAGE Publications, pp. 218-242.

Schylander, E. and Martinuzzi, A. (2007), "ISO 14001 - Experiences, effects and future challenges: a national study in Austria", Business Strategy and the Environment, Vol. 16, No. 2, pp. 133-147.

Shiba, S., Graham, A. and Walden, D. (1993), A new American TQM. Four practical revolutions in management, Portland, Oregon, Center for Quality Management. Productivity Press.

Sila, I. and Ebrahimpour, M. (2002), "An investigation of the total quality management survey based research published between 1989 and 2002", International Journal of Quality and Reliability Management, Vol. 19 No. 7, pp. 902-970.

Young, J. and Wilkinson, A. (2001), "Rethinking total quality management", Total Quality Management, Vol. 12, No. 2, pp. 247-258. 
van der Wiele, A., Williams, A.R.T. and Dale, B.G (2000), " Total Quality Management. Is it a fad, fashion or fit?", Quality Management Journal, Vol. 7, No. 2, pp. 65-79.

Zobel, T. (2010), "Exploring the influence of organisational characteristics on benefits of environmental management systems", in Proceedings of $13^{\text {th }}$ QMOD Conference on Quality and Service Sciences ICQSS, Cottbus, Germany, August 30 - September 1.

\begin{abstract}
ABOUT THE AUTHORS
Bjarne Bergquist is Professor and Chair of Quality Technology \& Management at Luleå University of Technology, Sweden. He has published in Production, Planning \& Control, Quality Engineering, Quality and Reliability Engineering International, International Journal of Lean Six Sigma, Total Quality Management \& Business Excellence, The TQM Journal, International Journal of Six Sigma and Competitive Advantage, Quality Management Journal, and other journals and books in the field of quality improvements. His current research interests are in improvement programs and in use of methods and tools for improvements, particularly in the continuous process industries. E-mail: bjarne@1tu.se
\end{abstract}

Henrik Eriksson is as a researcher at the division of Quality Sciences and the Centre for Healthcare Improvement (CHI) at Chalmers University of Technology, Sweden. He earned his doctoral degree at Luleå University of Technology in Quality Technology \& Management in 2004. He has a background as a healtcare quality manager. His research interests include: Quality Improvement in healthcare, Quality management in theory and practice, Process Management and its applications, Business Excellence and Quality Awards, and Quality Management in Small and Medium sized organizations. Email: henrik.eriksson@chalmers.se

Rickard Garvare, Ph.D. is Professor of Quality Management at the Department of Business Administration, Technology and Social Sciences at Luleå University of Technology, Sweden. He has experience of teaching a variety of courses in the master and doctoral programs. Garvare's present research efforts are focused on adoption and implementation of quality related methodologies, exploring causes to gaps between knowledge and practice mainly in health care related organizations and systems. E-mail: rickard.garvare@ltu.se

Jacob Hallencreutz, is Senior Partner at Implement MP AB in Stockholm, Sweden, focusing on change management consultancy. Jacob has more than 15 years of practical management experience from both service and manufacturing companies. Jacob is also a $\mathrm{PhD}$ researcher at Lulea University of Technology. His research interest focuses broadly on how to accelerate and execute 
organizational change, with a specific focus on management models based on systems thinking. E-mail: jacob.hallencreuz@implement.se

Jostein Langstrand has a MSc and $\mathrm{PhD}$ in Quality Technology and Management. He is currently a Lecturer at the Departnement of Management and Engineering and is also active within the HELIX VINN Excellence Centre at Linköping University. His research is mainly directed towards the dissemination and implementation of management concepts. E-mail: jostein.langstrand@liu.se

Erik Vanhatalo is an assistant professor and a senior lecturer of Quality Technology and Management, Luleå University of Technology, Luleå, Sweden. He holds a PhD in Quality Technology and Management and a Master's degree in Industrial and Management Engineering both from Luleå University of Technology. His current research is mainly focused on the use of statistical methods in the process industry, especially experimental design and statistical process control. E-mail: erik.vanhatalo@ltu.se

Thomas Zobel in an assistant professor and senior lecturer of Environmental Management, Luleå University of Technology, Luleå, Sweden. He is specialized in corporate environmental management and has extensive experience in studying the implementation of voluntary environmental and sustainability commitments at company level. E-mail: thomas.zobel@ltu.se 